\title{
Physiological Impact of Statins Experimentally Revealed on Ants
}

\author{
Marie-Claire Cammaerts ${ }^{* *}$ and David Cammaerts ${ }^{2}$ \\ 'Independent Researcher, 27, square du Castel Fleuri, 1170, Bruxelles, Belgium; mtricot@ulb.ac.be \\ ${ }^{2}$ Independent Researcher, 113, Rue Silvela, 4900, Spa, Belgium
}

\begin{abstract}
Statins are nowadays largely used for caring of persons suffering from hypercholesterolemia. Their use was recently debated. We studied the effects of simvastatin on ants as models. We observed that this product enlarged the insects' sugar food consumption, reduced their general activity, linear speed, orientation ability, trail following, audacity, tactile and pain perception, cognition, ability in escaping from an enclosure, visual and olfactory conditioning ability (thus their shortterm memory), and their middle term visual and olfactory memory. Simvastatin did not affect the ants' relationship with their nestmates. The ants developed adaptation to some adverse effects of simvastatine, and presented no habituation to beneficial effects. Also, simvastatine did not lead to dependence. Consequently, even if simvastatin is efficient in reducing the amount of cholesterol, and leads to some adaptation, no habituation and no addiction, it has several harmful effects. This drug should thus be used only in case of high necessity, never for children, and natural alternative with very few adverse effects should be advantageously researched.
\end{abstract}

Keywords: Cholesterol, Cognition, Food Consumption, Locomotion, Memory

\section{Introduction}

Nowadays, excess of cholesterol in blood (hypercholesterolemia) is one of the most frequent pathology, which can lead to infarcts, AVC, phlebitis, and ocular deficiencies. It must be treated, i.e., the amount of cholesterol in blood must be artificially decreased. This can be done thanks to an adequate diet, but often, this is not enough for sufficiently decreasing the amount of cholesterol of patients. Drugs have thus been produced for caring of these patients. The most used are statins. They inhibit the enzyme hydroxymethylglutaryl CaA reductase (HMG-CoA reductase) which acts during the synthesis of cholesterol. One of the most used statin is simvastatin (Figure 1). It has been evaluated as having no adverse effects, and had thus been and is still nowadays largely used, all over the world ${ }^{1}$. However, some health problems seem to occur for such treated persons ${ }^{2}$. Based on our previous studies of substances considered as inoffensive and for which we observed harmful effects on ants ${ }^{3,4}$, we think that adverse effects of novel drugs or food complements are often not adequately and/or sufficiently divulgated at the time of their first production, but are only later, progressively, reported by researchers and practitioners. We also think that not all studies are made without conflict of interest. Consequently, we aimed to examine the potential adverse effects of simvastatin using ants as biological models. Our status of independent researchers prevents us of having any conflict of interest.<smiles>CCC(C)(C)C(=O)O[C@H]1C[C@@H](C)C=C2C=C[C@H](C)[C@H](CC[C@@H]3C[C@@H](O)CC(=O)O3)[C@H]21</smiles>

Figure 1. Chemical structure of simvastatin, the largely used drug for decreasing cholesterol amount in blood. 
Below, we detail why we have no conflict of interest; we summarize the information available on the effects of simvastatin; we state why we use ants as biological models, which species we used, and which physiological traits we intended to examine.

We are ethologist and biologist; we work on ants and aquatic macro invertebrates as independent researchers. We are not funded by organization, institution, Drugs Company or lobby group. We have thus no conflict of interest about potential harmful effects of simvastatine.

The notice joined to simvastatin package states that persons suffering from hypercholesterolemia must have a diet with a very low amount of cholesterol, and that they must consume each day $20 \mathrm{mg}$ or $40 \mathrm{mg}$ of simvastatin. Little is said about potential, seldom observed, adverse effects induced by the drug, such as pain in muscles, in liver and in kidneys. The Internet link 'www.Doctissimo. $\mathrm{fr} /$ medicament-SIMVASTATINE-MYLAN.htm' boasts the beneficial effect of simvastatin, and says few about 'not very important' adverse effects such as difficulty in walking, muscular cramps.

Most biological processes are similar for all animals, including humans ${ }^{4,5}$. Consequently, many animals are used for exploring physiology and ethology ${ }^{6}$. Invertebrates are more and more used because they have a rapid development, are small and can be collected in large samples ${ }^{7}$. A few species are commonly used: Dendrocelium lacteum, Caenorhabditis elegans, Aplysia californica, Tribolium castaneum, Drosophila melanogaster, Apis mellifer ${ }^{5}$. The insects, above all the hymenoptera such as bees, are often employed ${ }^{8}$. Ants can also be used. They are highly evolved eu-social insects as for their mouth parts ${ }^{9}$, and possess numerous glands producing pheromones ${ }^{10}$. Their colonies present a complex labor division, age-based polyethism and social regulation ${ }^{5,11}$. They take care of their brood, construct complex nests, mark their habitat and their environment with different pheromones ${ }^{5,11}$. They communicate thanks to informative chemical signals ${ }^{5,12}$. They navigate thanks to memorized elements $^{5,12}$; they recruit nestmates ${ }^{5,11,12}$; they clean their nest and even managing cemeteries ${ }^{11,12}$. Researchers can thus use ants as biological models to study the impacts of products, environmental elements and situations ${ }^{5}$.

We study ants of the genus Myrmica since 1969, in particular Myrmica sabuleti, Meinert $1861^{5,13}$. We have studied its ecology, eyes, angle of vision, vision, navigation, learning capacities, collect of food ${ }^{5,13}$, and ontogenesis of some of their abilities ${ }^{14}$. Studying the effect of age, activity and diet on the learning ability of M. ruginodis led us to suppose that they could be used as models ${ }^{5,15}$. This was confirmed when studying the effects of several alkaloids, of nicotine, of morphine and quinine, buprenorphine and methadone, of fluoxetine, of anafranil and efexor, ${ }^{3}$ of paroxetine, ${ }^{4}$ of carbamazepine, ${ }^{5}$ of alprazolam, and of sweeteners as well as food complements ${ }^{16,17}$ on Myrmica species. Each time, we found effects like those observed on humans and brought precise information on these effects. We also revealed other effects which may exist for humans. In the present work, we worked again on $M$. sabuleti for studying the harmful impacts of simvastatin.

We intended to examine 18 physiological traits, first on ants under normal diet, secondly on the same ants consuming simvastatine, then 4 other traits only on ants consuming or having consumed simvastatine. These 18 traits are: meat consumption, sugar water consumption, general activity, linear speed, angular speed, orientation towards an alarm signal, following a trail, reluctance in moving on an unknown apparatus, tactile ("pain") perception, caring of the brood, cognitive ability, aggressive behavior against nestmates, aggressiveness against aliens, ability in escaping from an enclosure, visual conditioning ability, visual memory, olfactory conditioning ability, and olfactory memory. The 4 other traits are: adaptation to the drug consumption, habituation to the drug effect, dependence on the drug use, and vanishing of the impacts of simvastatin after the end of its consumption.

Adaptation occurs when some decrease of adverse effects is noted. Habituation occurs when decrease of beneficial effects is observed. Dependence exists when individuals consuming the drug prefer food containing the drug instead of food free of it.

\section{Material and Methods}

Most of the material and methods here used are similar to those previously used for examining the adverse effects of several products consumed by humans using ants as material ${ }^{4,5,16,17}$. Having already detailed them, we here summarize these protocols.

\subsection{Collection and Maintenance of Ants}

All the experiments were conducted on two colonies of $M$. sabuleti, and a few ones on another colony, the 
three colonies having been collected in the Aise Valley (Ardenne, Belgium) in June 2016. They were maintained in glass tubes half filled with water and deposited in trays $(34 \mathrm{~cm} \times 23 \mathrm{~cm} \mathrm{x} 4 \mathrm{~cm})^{5}$. They were fed with an aqueous solution of sugar and cut Tenebrio molitor larvae (Linnaeus, 1758). Laboratory parameters were optimum for the species ${ }^{17}$. The ants are here often named 'nestmates' as usually done by persons working on social insects.

\subsection{Simvastatin Solution Given to Ants}

A package of Zocor Sandoz was furnished by the pharmacy Wera (1170, Bruxelles, Belgium). Humans are advised to consume $20 \mathrm{mg}$ or $40 \mathrm{mg}$ simvastatin per day. Humans consume about one liter of water per day (not including the water contained in food). Thus, under simvastatin diet, they consume, per day, 20 or 40 $\mathrm{mg}$ of the drug and one liter of water. Insects, thus ants, drink proportionally about ten times less water than mammals. Consequently, a solution of $40 \mathrm{mg}$ of statin in $100 \mathrm{ml}$ water must be given to ants so that they lived under a simvastatin diet similar to that lived by humans. A tablet of $40 \mathrm{mg}$ simvastatin was thus dissolved in 100 $\mathrm{ml}$ of sugar water. This solution was delivered to the ants in small tubes used for providing them with sugar water. It was daily checked if ants effectively drunk the solution of simvastatin, and they did. The cotton plugging the tubes was refreshed every 2-3 days, while the entire solution was renewed every 7 days. Experiments on ants under simvastatin diet started after the colonies had the adequate solution for 24 hours.

\subsection{Sugar Water and Meat Consumption, and General Activity}

As previously ${ }^{17}$, the ants drinking the sugar water, eating the T. molitor larvae, and being in activity anywhere were counted six times per day, for six days. The daily mean

Table 1. Effect of simvastatin on ants' sugar water and meat consumption, and on their general activity. Ants of colonies A and B drinking sugar water, eating meat, and being active were counted 6 times per day (Daily counts) during 6 days, first while under normal diet, then while under statin diet. Daily means, and the average of the daily means were established. Statistical results are given in the text. Briefly, under statin diet, ants consumed largely more sugar water and were slightly less active

\begin{tabular}{|c|c|c|c|c|c|c|}
\hline & \multicolumn{3}{|c|}{ Normal diet } & \multicolumn{3}{|c|}{ Diet with silvastatin } \\
\hline Days & meat & sugar water & activity & meat & sugar water & activity \\
\hline \multicolumn{7}{|c|}{ Daily counts } \\
\hline I A & 111101 & 110111 & 567633 & 011211 & 222433 & 445658 \\
\hline B & 000111 & 111111 & 322446 & 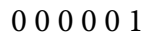 & 222222 & 567678 \\
\hline II A & 101221 & 011111 & 223445 & 111121 & 777122 & 123767 \\
\hline B & 111110 & 010011 & 388634 & 000111 & 00000011 & 333344 \\
\hline III A & 222223 & 010110 & 234869 & 010010 & 222221 & 323677 \\
\hline B & 111011 & 343222 & 46610810 & 000122 & 333112 & 565776 \\
\hline IV A & 101001 & 010111 & 445547 & 101101 & 222878 & 545878 \\
\hline B & 101111 & 110211 & 787788 & 000100 & 343778 & 121566 \\
\hline V A & 010101 & 101110 & 223534 & 111334 & 545332 & 232767 \\
\hline B & 101110 & 010101 & 878988 & 111000 & 554112 & 434423 \\
\hline VI A & 010010 & 101111 & 456788 & 221101 & 565454 & 456565 \\
\hline B & 010010 & 111111 & 109991010 & 211010 & 333343 & 343445 \\
\hline \multicolumn{7}{|c|}{ Daily means } \\
\hline I & 0.67 & 0.92 & 4.25 & 0.58 & 2.33 & 5.92 \\
\hline II & 1.00 & 0.67 & 4.33 & 0.83 & 2.33 & 3.83 \\
\hline III & 1.50 & 1.58 & 6.33 & 0.58 & 2.00 & 5.25 \\
\hline IV & 0.67 & 0.83 & 6.17 & 0.42 & 5.08 & 4.83 \\
\hline $\mathrm{V}$ & 0.58 & 0.58 & 5.42 & 1.33 & 3.33 & 3.92 \\
\hline VI & 0.33 & 0.92 & 7.92 & 0.83 & 4.00 & 4.50 \\
\hline \multicolumn{7}{|c|}{ Average of daily means } \\
\hline & 0.79 & 0.92 & 5.74 & 0.75 & 3.18 & 4.71 \\
\hline
\end{tabular}


of these counts was established (Table 1, Daily means). They were compared to the six daily means obtained for ants under normal diet, using the non-parametric test of Wilcoxon ${ }^{18}$. Moreover, we calculated the mean of the daily means (Table 1, Average of daily means).

\subsection{Locomotion and Orientation}

The experiments were made on ants walking in their tray; the locomotion was assessed giving nothing to the ants, the orientation was assessed by presenting them with a nestmate tied to a piece of white paper ${ }^{4,5}$. Such a tied worker emits its alarm pheromone. Each time, the movement of 20 ants of each colony $(n=20$ ants $x 2$ colonies $=40$ trajectories) was recorded and the trajectories were analyzed using specifically designed software (Figure 2B) ${ }^{4,5,19}$. The assessed variables (linear speed, angular speed, orientation) are defined as previously ${ }^{4,5,19}$. Each distribution of 40 values was characterized by its median and quartiles (Table 2) and the distributions obtained for ants consuming simvastatin were compared to those obtained for ants under normal diet, using the nonparametric $\chi^{2}$ test $^{5,18}$.

\subsection{Following a Trail}

The methodology set up 30 years ago was once more

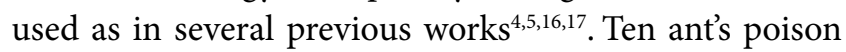
glands were isolated in $500 \mu \mathrm{l}$ hexane and $50 \mu \mathrm{l}$ of the solution was deposited on a pencil drawn circle $(\mathrm{R}=5$ $\mathrm{cm})$ divided into 10 angular degrees arcs. The response of 20 ants of each colony was assessed by the number of arcs of 10 angular degrees they walked along the trail (Figure 2C). Each distribution of values was characterized by its median and quartiles (Table 2), and the distribution obtained for ants consuming simvastatin was compared to that obtained for ants under normal diet using the nonparametric $\chi^{2}$ test.

\subsection{Reluctance of Moving on an Unknown Apparatus}

As previously ${ }^{4,5,16,17}$, a cylindrical tower made of white paper was deposited in the ants' tray, and the ants present on this apparatus were counted 12 times in $12 \mathrm{~min}$ (Figure 2D, 3D). The mean and extremes of the obtained values were established (Table 2). The values obtained for ants under the two kinds of diet were compared to one another using the non-parametric Wilcoxon test ${ }^{18}$, pulling the values obtained for the two colonies during each successive time period of two minutes.

\subsection{Tactile ("Pain") Perception}

A physiological adverse effect of a drug may be impacting the sensitive nervous system. It is the reason why we assessed the ants' locomotion on a rough substrate: if they perceived correctly the uncomfortable character of the substrate, they will walk with difficulties, slowly, sinuously; if their tactile perception is impacted, they will walk more confidently. As previously $y^{4,5,16,17}$, for each colony, 12 ants were deposited in an apparatus provided with rough emery $n^{\circ} 280$ paper. The linear and the angular speed of 12 ants of each colony $(n=24$; Table 2$)$ walking on this rough substrate were quantified. The values obtained for ants consuming simvastatin were compared to the values obtained for ants under normal diet using the non-parametric $\chi^{2}$ test.

Table 2. Effect of simvastatin on six ethological and physiological traits. Experiments, assessments and statistics are detailed in the text. There were obtained on ants of two colonies while they were under normal then statin diet. Median (and quartiles) values or mean [and extremes] are given. Briefly, statin decreased the ants' linear speed, orientation ability, trail following, audacity, and tactile perception, and increased their sinuosity

\begin{tabular}{lcc}
\hline Traits & normal diet & diet with simvastatine \\
\hline Linear speed (mm/s) & $12.9(11.5-13.9)$ & $10.3(9.2-11.2)$ \\
Angular speed (ang.deg./cm) & $138(117-157)$ & $178(162-209)$ \\
Orientation (ang. deg.) & $36.8(26.4-47.3)$ & $69.3(55.8-86.2)$ \\
Trail following ( $\mathrm{n}^{\circ}$ arcs) & $10.0(7.5-14.3)$ & $3.0(2.0-5.3)$ \\
Audacity ( $\mathrm{n}^{\circ}$ ants) & $1.40[0-2]$ & $0.50[0-1]$ \\
Tactile (pain) perception: & & \\
linear speed (mm/s) & $5.9(4.3-6.6)$ & $7.5(6.5-8.5)$ \\
angular speed (ang.deg./s) & $257(217-304)$ & $172(136-204)$ \\
\hline
\end{tabular}




\subsection{Caring of Brood}

As previously $y^{4,5,16,17}$, for each colony, larvae were taken out of the nest and set in front of the entrance. The ants' behavior in front of five of these larvae was observed (Fig. $2 \mathrm{~F}, 3 \mathrm{~F}$ ), and the larvae among these five ones still not replaced in the nest after $30 \mathrm{~s}, 2,4,6,8$, and 10 min were counted. The results obtained for each colony were pulled (Table 3), and the sums obtained for ants consuming simvastatin were compared to those obtained for these ants under normal diet using the non-parametric Wilcoxon test.

\subsection{Cognition}

The methodology set up while examining the effects of nicotine was once more used, as in ${ }^{16,17}$. For each colony, 15 ants were set all together in the initial loggia of an apparatus provided with a twist and turns path between that loggia and a larger one lying beyond the difficult path (Figures 2J, 3J). The ants present in each two loggia were counted after $30 \mathrm{~s}, 2,4,6,8,10$ and $12 \mathrm{~min}$. The numbers obtained for the two colonies were added (Table 3), and the sums obtained for ants consuming simvastatin were compared to those obtained for these ants under normal diet using the non-parametric Wilcoxon test.

\subsection{Aggressive Behavior Against Nestmates and Aliens}

This treat was assessed as previously ${ }^{16,17}$. Five dyadic encounters were realized for each colony. Each time, one ant of colony A or B was observed for $5 \mathrm{~min}$ and the number of times it did nothing (level 0 of aggressiveness), touched the other ant with its antennae (level 1), opened its mandibles (level 2), gripped and/or pulled the other ant (level 3), tried to sting or stung the other ant (level 4) were counted. The numbers recorded for the two colonies were added (Table 3). The results obtained for ants consuming simvastatin were compared to those obtained for ants under normal diet using the non-parametric $\chi^{2}$ test. The ants' aggressiveness was also assessed by 'a' equaled to the number of recorded aggressiveness levels $2+3+4$ divided by the number of recorded levels $0+1$.

Table 3. Effects of simvastatin on five ants' ethological or physiological traits. Ants of two colonies were tested when under normal then statin diet. Experimental details and statistical results are given in the text. Statin affected ants' larvae re-entering, cognition, escaping ability, but not their aggressiveness. Levels: $0=$ no reaction, $1=$ antennae movement, $2=$ mandibles opening, $3=$ gripping, $4=$ stinging; ' $a '=n^{\circ}$ levels $(2+3+4) /(0+1)$

\begin{tabular}{ccc}
\hline \multicolumn{1}{c}{ Traits } & normal diet & diet with simvastatin \\
\hline Brood caring: larvae among 10 not & t: 30s 246810 & t: 30s 246810 \\
re-entered in the course of 10 min & $n^{\circ} 1086530$ & $n^{\circ} 10108775$
\end{tabular}

Cognition: ants in front and beyond twists and turns in the course of $12 \mathrm{~min}$

Aggressiveness against nestmates

Aggressiveness against aliens

Escaping from an enclosure: ants in and out of the enclosure in the course of $12 \mathrm{~min}$

$\begin{array}{cc}\mathrm{t}^{\circ} \text { in front } \mathrm{n}^{\circ} \text { beyond } & \mathrm{t}^{\circ} \text { in front } \mathrm{n}^{\circ} \text { beyond } \\ 30 \mathrm{~s} 280 & 30 \mathrm{~s} 300 \\ 2230 & 2290 \\ 4160 & 4270 \\ 6132 & 6240 \\ 8122 & 8220 \\ 10122 & 10220 \\ 12114 & 12210\end{array}$

levels 01234 'a' $n^{\circ} 76509000.07$

levels 01234 'a' $\mathrm{n}^{\circ} 817710000.06$

levels 01234 'a'

levels 01234 'a' $n^{\circ} 6195664185.52$ $n^{\circ} 123664674.96$

30s 24681012

in 121197543

out 0135789 variable $=9 / 12=0.75$ in 12121111121111

out 0011011

variable $=3 / 12=0.08$ 


\subsection{Escaping from an Enclosure}

For each colony, six ants were enclosed in a reversed polyacetate glass deposited in the ants' tray ${ }^{16,17}$. The rim of the bottom had been provided with a small notch for giving to the ants the opportunity to escape. The ants' ability in escaping was assessed by their numbers still under the glass and those escaped after $30 \mathrm{~s}, 2,4$, $6,8,10$ and $12 \mathrm{~min}$. The results obtained for the two colonies were pulled (Table 3 ), and the sums obtained for ants consuming simvastatin were compared to those previously obtained for ants under normal diet using the non-parametric Wilcoxon test. We also calculated the variable " ${ }^{\circ}$ of ants escaped after $12 \mathrm{~min} / 12$ " for each kind of diet (Table 3).

\subsection{Visual and Olfactory Conditioning and Memory}

The methodology is presently well established ${ }^{4,5,16,17}$. These traits were quantified on colonies $\mathrm{A}$ and $\mathrm{B}$ consuming simvastatine, and on the other colony $(\mathrm{C})$ never provided with this drug. At a time, a green hollow cube was set above the sugar water supply, and the ants underwent so visual operant conditioning. After the end of visual conditioning experiment, pieces of rosemary were set near the sugar water supply, and the ants underwent then olfactory operant conditioning. Tests were performed during conditioning acquisition, then during conditioning loss. As usually $y^{4,5,16,17}$, ants were individually tested in a Y-apparatus provided with a green hollow cube or pieces of rosemary in one branch. Choosing the way with the cue was considered as giving the correct response (Figure $2 \mathrm{~K}, \mathrm{~L}$ ). The procedure used for conducting a test is summarized in previous works ${ }^{4,5,16,17}$. For each test, the numbers of ants under simvastatin diet (10 ants $\mathrm{x} 2$ colonies $=20$ choices), and of ants under normal diet $(\mathrm{n}=$ 10), which gave the correct response were recorded, and the percentage of correct responses established (Table 4). The numerical results obtained for ants under the two kinds of diet were statistically compared using the nonparametric Wilcoxon test ${ }^{4,5}$.

\subsection{Adaptation to Simvastatin Consumption}

After the ants consumed simvastatin for 12 days, their linear and angular speeds were again assessed as they had been after two days of consumption for examining if ants develop adaptation to that drug. The values obtained after
12 days were compared to the control values and to those obtained after two days of consumption using the nonparametric $\chi^{2}$ test.

Table 4. Impact of simvastatin on ants' visual and olfactory conditioning and memory. Ants were trained to a visual or an olfactory cue, and tested over time in a $\mathrm{Y}$ apparatus provided with the cue in one of its branch. The table gives the numbers of correct response given by ten ants of each colony and the conditioning score of ants under normal or simvastatin diet. Details and statistical analysis are given in the text. Statin impacted the ants' ability in acquiring conditioning, and in retaining it. The drug affected thus the ants' short and middle term memories

\begin{tabular}{|c|c|c|c|c|c|}
\hline $\begin{array}{l}\text { Traits } \\
\text { Time (hrs) }\end{array}$ & \multicolumn{5}{|c|}{$\begin{array}{l}\text { under normal diet under statine diet } \\
\text { Colony C \% colony A colony B \% }\end{array}$} \\
\hline \multicolumn{6}{|c|}{ Visual conditioning } \\
\hline 7 & 7 & 70 & 5 & 7 & 60 \\
\hline 24 & 8 & 80 & 5 & 7 & 60 \\
\hline 31 & 8 & 80 & 6 & 6 & 60 \\
\hline 48 & 8 & 80 & 6 & 6 & 60 \\
\hline 55 & 8 & 80 & 5 & 7 & 60 \\
\hline 72 & 8 & 80 & 6 & 5 & 55 \\
\hline \multicolumn{6}{|c|}{ Visual memory } \\
\hline 7 & 8 & 80 & 3 & 6 & 45 \\
\hline 24 & 7 & 70 & 7 & 3 & 50 \\
\hline 31 & 8 & 80 & 5 & 5 & 50 \\
\hline 48 & 7 & 70 & 5 & 5 & 50 \\
\hline 55 & 7 & 70 & 5 & 5 & 50 \\
\hline 72 & 7 & 70 & 5 & 5 & 50 \\
\hline \multicolumn{6}{|c|}{ Olfactory conditioning } \\
\hline 7 & 7 & 70 & 6 & 5 & 55 \\
\hline 24 & 8 & 80 & 5 & 7 & 60 \\
\hline 31 & 8 & 80 & 8 & 5 & 65 \\
\hline 48 & 9 & 90 & 6 & 7 & 65 \\
\hline 55 & 9 & 90 & 6 & 7 & 65 \\
\hline 72 & 9 & 90 & 6 & 6 & 60 \\
\hline \multicolumn{6}{|c|}{ Olfactory memory } \\
\hline 7 & 9 & 90 & 6 & 6 & 60 \\
\hline 24 & 8 & 80 & 5 & 6 & 55 \\
\hline 31 & 8 & 80 & 5 & 7 & 60 \\
\hline 48 & 7 & 70 & 6 & 5 & 55 \\
\hline 55 & 8 & 80 & 5 & 7 & 60 \\
\hline 72 & 8 & 80 & 6 & 4 & 50 \\
\hline
\end{tabular}

\subsection{Habituation to Simvastatin Consumption}

After the ants had consumed simvastatin for 13 days, their audacity was again assessed as it has been after 
three days of consumption for examining if they develop habituation to the only slight beneficial effect of the drug, here revealed, i.e., some reduction of straightforwardness. The results obtained after 13 days of consumption were statistically compared to those obtained after 3 days and to the control ones using the non-parametric Wilcoxon tests as previously done (see above).

\subsection{Addiction on Simvastatin}

The methodology was that previously used ${ }^{4,5,16,17}$. After the ants had consumed simvastatin for 14 days, for each colony, 15 ants were transferred into a tray in which two tubes $(\mathrm{h}=2.5 \mathrm{~cm}$, diam. $=0.5 \mathrm{~cm})$ had been laid, one containing sugar water, the other a sugared solution of simvastatin. In one tray, the tube containing the drug was located on the right; in the other tray, it was located on the left. The ants consuming each liquid were counted 12 times over $15 \mathrm{~min}$, and the mean value was calculated for each kind of liquid. The sums of the values obtained for each colony were compared to the numbers resulting from a random choice using the non-parametric goodness of fit $\chi^{2}$ test $^{18}$.

\subsection{Vanishing of the Impacts of Simvastatin After the End of its Consumption}

The methodology has previously been set $\mathrm{up}^{4,5,16,17}$. A fresh solution of simvastatin was given to the ants, and 12 hours later, was changed for sugar water free of the drug. Since that weaning time, the ants' audacity was assessed as it has been before the ants consumed simvastatin as well as after they had consumed the drug for 4 and 13 days, this after several time periods over time. The results then obtained were compared to those obtained after 4 days of simvastatin consumption and to the control ones using the non-parametric Wilcoxon tests as previously done (see the paragraph 'Reluctance of Moving on an Unknown Apparatus'). The experiment ended when the ants' audacity was again similar to that exhibited under normal diet (Table 6, Figure 4).

\section{Results}

\subsection{Meat and Sugared Food Consumption, General Activity}

Results are given in Table 1. Under simvastatin diet, the ants were as numerous on the meat food site as while consuming no simvastatin $(\mathrm{N}=6, \mathrm{~T}=-16, \mathrm{P}=0.156)$. On the contrary, they were three more times numerous on the sugared food site, and this result was significant $(\mathrm{N}=$ $6, \mathrm{~T}=+21, \mathrm{P}=0.016)$. The ants were somewhat less active while being under simvastatin diet than while being under normal diet, and this result was significant $(\mathrm{N}=6$, $\mathrm{T}=20, \mathrm{P}=0.031$ ). This decrease of activity began after the ants had consumed simvastatin for two days, and became more pronounced over the first week of consumption.

\subsection{Linear and Angular Speeds}

Numerical results can be found in Table 2. Under statin diet, the ants moved at a lower linear speed and a higher sinuosity than when they did not consume that drug. This was significant (linear speed: $\chi^{2}=20.75, \mathrm{df}=2, \mathrm{P}$ $<0.001$; angular speed: $\left.\chi^{2}=29.82, \mathrm{df}=2, \mathrm{P}<0.001\right)$. Such a decrease of locomotion was observed while experimenting (Figures 2A, 3A). Young ants seemed to be more impacted than older ones, and might have also their antennae movements perturbed (Figure. 3A).

\subsection{Orientation towards an Alarm Signal}

The Table 2 gives the numerical results. Under statin diet, ants oriented themselves less well towards an alarm signal than while being under normal diet. This was observed while experimenting (Figures 2B, 3B), and was confirmed by the numerical and the statistical results. Indeed, the difference of ants' orientation ability under the two diets was significant $\left(\chi^{2}=16.34, \mathrm{df}=2, \mathrm{P}<0.001\right)$.

\subsection{Trail following Behavior}

This trait was impacted by simvastatin consumption (Table 2; Figures 2C, 3C). Under normal diet, the ants walked on a circular trail meanly along 10 arcs of 10 ang. deg. Under statin diet, they did so along only meanly 3 arcs of 10 ang. deg. The difference of ants' trail following when under each kind of diet was significant: $\chi^{2}=36.42$, $\mathrm{df}=2, \mathrm{P}<0.001$.

\subsection{Audacity}

Numerical results are given in Table 2. Under statin diet, ants were less incline to come onto an unknown apparatus (Figures 2D, 3D) than while being under normal diet. The difference of behavior between ants under the two kinds of diet was significant $(\mathrm{N}=5, \mathrm{~T}=-15, \mathrm{P}=0.031)$. Ants consuming statin generally stopped in front of the apparatus; they seldom walked on it, on its bottom, and no ant climbed on the tower. 


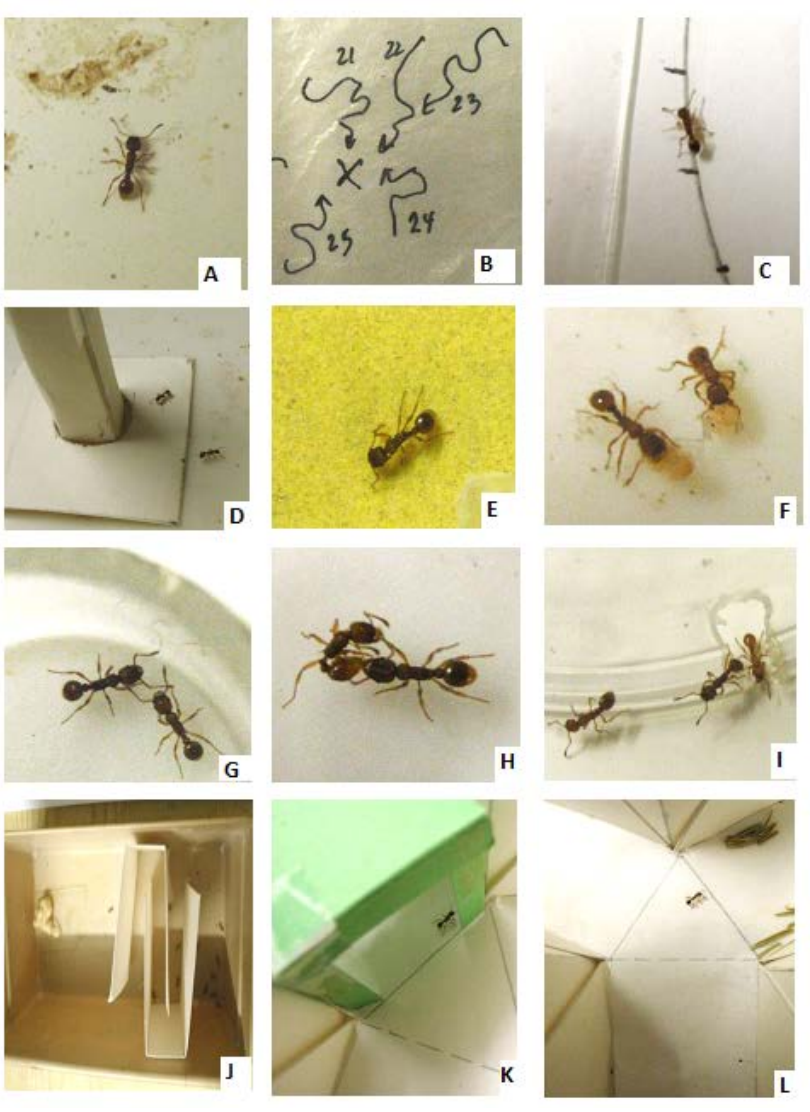

Figure 2. Some views of the control experiments. (A) An ant walking on its foraging area, as usual. (B) Recorded trajectories of ants perceiving a tied nestmates set at the place marked by a cross. The ants oriented themselves towards their tied nestmate. (C) An ant following a circular trail. (D) Ants coming onto an unknown apparatus. (E) An ant walking with difficulties and pain on a rough substrate. (F) Two ants taking care of their brood. (G) Two nestmates in the course of a dyadic encountering; the ants were not at all aggressive. $(\mathrm{H}) \mathrm{An}$ ant (on the left) encountering an alien and aggressing it. (I) Ants able to escape out of an enclosure, through a small exit hole. (J) Ants crossing a path with twists and turns for reaching a large loggia; one ant could already reach that large loggia. (K) An ant presently under operant conditioning to a hollow green cube giving, in a Y maze, the correct response, i.e. choosing the way with the cue. (L) An ant presently under operant conditioning to rosemary giving, in a Y maze, the correct response, i.e. choosing the way with the cue.

\subsection{Tactile ("Pain") Perception}

This trait appeared to be impacted by statin consumption (Table 2; Figures 2E, 3E). While consuming no simvastatin, ants had difficulties in walking on the rough substrate.
They walked very slowly with a large sinuosity. While consuming statin, the ants walked on the rough substrate somewhat more frankly. The differences between ants under the two kinds of diet were significant (linear speed: $\chi^{2}=10.58, \mathrm{df}=2, \mathrm{P}<0.01$; angular speed: $\chi^{2}=20.29, \mathrm{df}$ $=2, \mathrm{P}<0.001$ ). Since under statin diet, the ants walked more slowly than when under normal diet (see above), the differences here revealed for ants' locomotion on a rough substrate suggest some decrease of the insects' tactile (potential "pain") perception.

\subsection{Brood Caring Behavior}

Photos are presented in Figs 2F, 3F, numerical results are given in Table 3 . Under statin diet, the ants still promptly came near the larvae experimentally set outside the nest, and took care of them. They held them in their mandibles and tried to replace them in the nest, but they could only badly do so. They seemed having difficulty in holding a larva. The difference between the two kinds of diet concerning the numbers of larvae replaced in the nest was significant $(\mathrm{N}=5, \mathrm{~T}=15, \mathrm{P}=0.031)$.

\subsection{Cognition}

Photos are given in Figures 2J, 3J, and numerical results in Table 3. Ants' cognition appeared to be impacted by statin consumption. While consuming no simvastatin, after the 12 experimental minutes, four ants were moving in the large loggia located beyond the 'twists and turns', and only 11 ants (among 30) were still in front of that difficult path. Under statin diet, no ant reached the large loggia, and 21 ants among 30 still moved in front of the twists and turns path after the 12 experimental minutes. The difference of ants' behavior while under the two kinds of diet was significant: large loggia: $\mathrm{N}=7, \mathrm{~T}=28, \mathrm{P}=0.008$; small $\operatorname{loggia}: \mathrm{N}=4, \mathrm{~T}=10, \mathrm{P}=0.06$. This result was in agreement with the ants' reluctance in coming onto an unknown apparatus (see above). Following experiments examined again potential impact of statin on cognitive abilities (see the paragraph 'Visual and Olfactory Conditioning and Memory' here below).

\subsection{Aggressiveness against Nestmates and Aliens}

Photos are shown in Figs 2G,H, 3G,H, and numerical results are given in Table 3. These traits were not, or 
slightly, affected by statin consumption. Under normal as well as statine diet, two nestmates meeting one another either did nothing, staying side by side or moving slowly, or touched one another with their antennae, making slow movements. The variable assessing their aggressiveness equaled 0.07 and 0.06 for ants under normal and statin diet respectively. In front of aliens, ants under normal diet as well as under statin diet were very aggressive. They very soon opened their mandibles and gripped the encounter. They even tried to sting it. A difference however existed between ants under the two kinds of diet: those under normal diet reacted sooner than those under statin diet; they were more prompt to attack, and were thus less often gripped and stung by the encounter. The variable assessing the ants' aggressiveness equaled 5.52 and 4.96 for ants under normal and statin diet respectively. This difference was significant $\left(\chi^{2}=10.41, \mathrm{df}=4,0.02<\mathrm{P}<0.05\right)$. This result and the lower general activity of ants consuming statin (see the above paragraph 'Meat and Sugared Food Consumption, General Activity') are in agreement.

\subsection{Escape Behavior}

This trait was impacted by statin consumption (Table 3, Figures 2I, 3I). Under normal diet, ants could with some delay escape from the enclosure. The variable assessing this ability equaled 0.75 . Under statin diet, the ants appeared to be nearly unable to do so; the variable equaled 0.08 . The difference between the two diets as for the numbers of ants still captive as well as of escaped ants was significant $(\mathrm{N}=6, \mathrm{~T}=+$ and -21 respectively, $\mathrm{P}=$ $0.016)$. This observation agreed with that on ants' audacity and cognition (see above).

\subsection{Visual and Olfactory Conditioning and Memory}

These traits were affected by statin consumption (Table 4). While ants under normal diet easily acquired visual conditioning, and reached a score of $80 \%$, those under statin diet only reached a score of $60 \%$. This difference was significant $(\mathrm{N}=6, \mathrm{~T}=-21, \mathrm{P}=0.016)$. The shortterm memory of the latter ants was thus affected by the drug. After removal of the visual cue, ants under normal diet still presented a conditioning score of $70 \%$; they kept thus $2 / 3$ of the acquired conditioning. Ants consuming simvastatin very quickly lost all the low conditioning they had acquired. The observed difference was significant $(\mathrm{N}=6, \mathrm{~T}=-21, \mathrm{P}=0.016)$. The ants' middle term visual memory was thus affected by the drug.

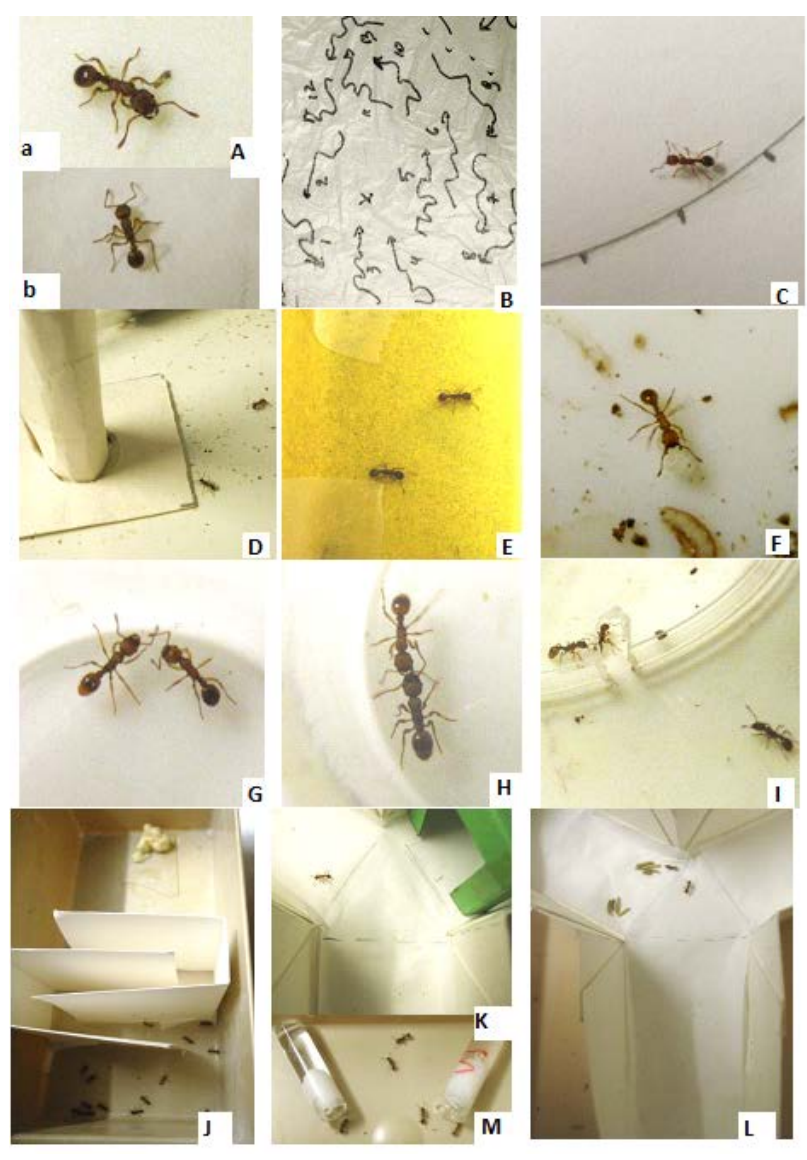

Figure 3. Some views of the experiments made on ants under simvastatin diet. (A) an ant walking with difficulty on its foraging area; $b$ : an ant unable to move its antennae. (B) Recorded trajectories of ants perceiving a tied nestmates set at the place marked by a cross. The ants did not orient themselves very well towards their tied nestmate. (C) An ant departing from a circular trail. (D) Two ants hesitating in coming onto an unknown apparatus. (E) Two ants walking with very few difficulties or pain on a rough substrate. $(\mathrm{F})$ An ant taking care of a larva. (G) Two nestmates in the course of a dyadic encountering; the ants were not at all aggressive. (H) An ant (on the above) encountering an alien and very little aggressing it. (I) Ants unable to escape out of an enclosure, through a small exit hole. (J) Ants trying to cross a path with twists and turns for leaving a small loggia; no ant could cross the passage. (K) An ant presently under operant conditioning to a hollow green cube giving, in a $\mathrm{Y}$ maze, the wrong response, i.e. choosing the way without the cue. (L) An ant presently under operant conditioning to rosemary hesitating, in a Y maze, as for the way to choose, i.e. that with the cue or the other. (M) Ants in presence of a sugared solution of simvastatin (tube with a $S$ in red) and sugar water free of that drug: they do not preferentially drink the solution containing the drug; they are not dependent on that drug. 
In the same way, while ants under normal diet reached an olfactory conditioning score of $70 \%$ after $7 \mathrm{hrs}$ of training, those under statin diet reached only a score of $55 \%$. After $72 \mathrm{hrs}$ of training, the former ants presented a score of $90 \%$, while the latter ones presented a score of only $60-65 \%$. The difference was significant $(\mathrm{N}=6, \mathrm{~T}=$ $-21, P=0.016)$. Statin impacted thus the ants' short-term memory. After the olfactory cue was removed since 72 hrs, ants under normal diet still presented a score of 70 $80 \%$; they kept thus $62.5 \%$ of their conditioning. The ants consuming statin presented a score of about $55 \%$ after the same time period without perceiving the olfactory cue; they kept thus only $33 \%$ of their conditioning. The difference of memory between ants under the two kinds of diet was significant $(\mathrm{N}=6, \mathrm{~T}=-21, \mathrm{P}=0.016)$. The drug affected thus the ants' middle term olfactory memory.

\subsection{Adaptation to Statin Consumption}

Numerical results, presented in Table 5, revealed that ants under statin diet for 12 days moved nearly as while being under normal diet. Their speed of locomotion was similar to the control one $\left(\chi^{2}=3.17, \mathrm{df}=2,0.20<\mathrm{P}<0.30\right)$ and higher than when having consumed statin for two days $\left(\chi^{2}=17.14, \mathrm{df}=2, \mathrm{P}<0.001\right)$. Their angular speed was however slightly higher than when under normal diet $\left(\chi^{2}=9.23, \mathrm{df}=2,0.001<\mathrm{P}<0.01\right)$, though being lower than the sinuosity exhibited after having consumed the drug for two days $\left(\chi^{2}=7.94, \mathrm{df}=3,0.02<\mathrm{P}<0.05\right)$. The ants developed thus some adaptation to the effect of statin on their locomotion. However, adaptation did not occur for all the adverse effects of the drug. Among others, visual and olfactory conditioning and memory, which were examined while ants consumed statin since five to nineteen days, were affected by the drug. Consequently, adaptation did not occur for the impact of the drug on the short and the middle term memory.

\subsection{Habituation to Statin Consumption}

In front of the apparatus, the ants behaved nearly like they did after having consumed the drug for 5 days: they stopped, turned back, calmly; they walked sometimes briefly on the apparatus but soon left it. The numerical results (Table 5) also show that ants still exhibited a low audacity after thirteen days of statin consumption. They statistically differed from the control ones $(\mathrm{N}=$ $5, \mathrm{~T}=-15, \mathrm{P}=0.031$ ), and did not differed from those obtained after 5 days of consumption $(\mathrm{N}=4, \mathrm{~T}=-6,+4$, $\mathrm{P}=0.438$ ). Consequently, no adaptation occurred as for the effect of simvastatin on the ants' audacity, excitation, straightforwardness; they stay rather calm, doing only what is "secure". This confers two beneficial properties to the drug on ants' behavior, i.e., having a calming effect, leading to no habituation to such an effect.

\subsection{Dependence on Statin Consumption}

In front of a sugar solution free of the drug and a similar solution containing statin, 14 ants of colony A choose the former solution and 8 ants the latter one, while 10 ants of colony $\mathrm{B}$ went drinking the former solution and 13 ones the latter one. Globally, 21 ants chose the solution containing statin and 24 ants the solution free of the drug. Such numbers did not statistically differ from those corresponding to a random choice by the ants $\left(\chi^{2}=0.08\right.$, $\mathrm{df}=1,0.70<\mathrm{P}<0.80)$. Ants develop thus no dependence on statine consumption.

\subsection{Decrease of the Effects of Simvastatine after its Consumption was Stopped}

Results are presented in Table 6 and Figure 4. The effect of simvastatin decreased slowly, regularly, nearly linearly over the running time. The effect at a time $t$ after weaning $\left(\mathrm{E}_{\mathrm{t}}\right)$ can thus be estimated using the linear function: $\mathrm{E}_{\mathrm{t}}=$

Table 5. Adaptation and habituation to simvastatin consumption. Assessments were made before ants consumed statin, after they had consumed this drug for 2-4days, and after they had consumed it for 12-13 days. Details and statistics are given in the text. Briefly, the ants adapted themselves to the adverse effect of statin on their locomotion, and did not become habituated to the reducing effect of the drug on their audacity

\begin{tabular}{lccc}
\hline Traits & control & 2-4 days & 12-13 days \\
\hline Adaptation & & & \\
$\begin{array}{l}\text { linear speed (mm/sec) } \\
\text { angular speed (ang. deg./cm) }\end{array}$ & $12.9(11.5-13.9)$ & $10.3(9.2-11.2)$ & $12.5(11.2-13.4)$ \\
$\begin{array}{l}\text { Habituation } \\
\text { audacity ( } \mathrm{n}^{\circ} \text { ants) }\end{array}$ & $1.40[0-2]$ & $0.50[0-1]$ & $0.45[0-1]$ \\
\hline
\end{tabular}


Table 6. Decrease of the effects of simvastatin after its consumption was stopped. The trait used for examining this decrease was the ants' audacity. The variable assessing this trait is defined in the text. Its values over the decrease are given in the table, together with the initial and the control ones and the result of statistical analysis (P; Wilcoxon test), and are graphically presented in Fig. 3. The decrease was slow, regular and lasted 38 hours

\begin{tabular}{lccc}
\hline experiment & Ants' audacity & Statistical difference with statin diet & Statistical difference with normal diet \\
\hline Under statin diet & $0.50[0-1]$ & & \\
Weaning since (hours) & & & \\
2 & $0.35[0-1]$ & & \\
4 & $0.40[0-1]$ & & $\mathrm{P}=0.031$ \\
$61 / 2$ & $0.45[0-1]$ & $\mathrm{P}=0.313$ & $\mathrm{P}=0.156$ \\
9 & $0.50[0-1]$ & & $\mathrm{P}=0.438$ \\
12 & $0.60[0-1]$ & & \\
16 & $0.65[0-1]$ & $\mathrm{P}=0.125$ & \\
18 & $0.80[0-2]$ & & \\
24 & $0.95[0-3]$ & $\mathrm{P}=0.031$ & \\
28 & $1.10[0-3]$ & & \\
$331 / 2$ & $1.25[0-3]$ & & \\
38 & $1.40[1-2]$ & & \\
& & & \\
Under normal diet & $1.40[0-2]$ & & \\
\hline
\end{tabular}

$E_{i}-3.75 t, E_{i}$ being the initial effect. Twelve hours after weaning, the ants' audacity still differed from the control one $(\mathrm{N}=5, \mathrm{~T}=-15, \mathrm{P}=0.031)$, and was similar to that under simvastatine diet $(\mathrm{N}=4, \mathrm{~T}=-3,+7, \mathrm{P}=0.313)$. After 24 hours, this trait was not different from that under statin diet $(\mathrm{N}=3, \mathrm{~T}=+6, \mathrm{P}=0.125)$ though not statistically differing from the control trait $(\mathrm{N}=5, \mathrm{~T}=+3$, $-12, \mathrm{P}=0.156$ ). Consequently, 24 hours after weaning, it was very little though still somewhat active. Later, 331/2 hours after weaning, ants' audacity tended to be similar to that of ants under normal diet: it was no longer different from the control one $(\mathrm{N}=4, \mathrm{~T}=+6,-4, \mathrm{P}=0.438)$ but statistically differed from that under simvastatin $\operatorname{diet}(\mathrm{N}=$ $5, \mathrm{~T}=15, \mathrm{P}=0.031$ ). Ultimately, 38 hours after weaning, the ants' audacity was identical to that presented under normal diet. Consequently, the effects of simvastatin lasted about $1 \frac{1}{2}$ days, decreasing slowly and regularly, what accounted for leading to no dependence (see the Discussion section).

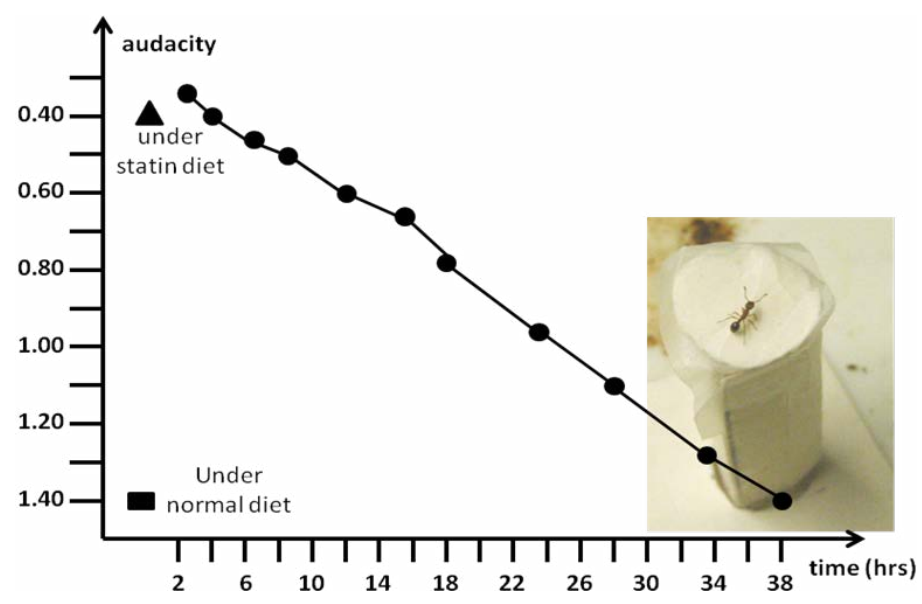

Figure 4. Decrease of the effect of simvastatin after its consumption was stopped. The numerical results are given in Table 6, and experimental details can be found in the text. 


\section{Discussion}

The use of statins for decreasing the amount of cholesterol in blood in persons suffering from hypercholesterolemia is presently rather debated. The studies of the harmful side effects of statins may have not been broadly divulgated, and/or may have been made with some conflict of interest. Here, ants were used as models for examining the effects of statins on 22 ants' physiological traits. We discovered that simvastatin increased the ants' sugar food consumption, decreased their general activity, speed of locomotion, ability in orienting, trail-following behavior, audacity, tactile perception, ability in re-entering larvae in the nest, cognition capabilities, ability in escaping from an enclosure, conditioning acquisition, visual and olfactory memory. This drug did not impact their care of brood, nor their aggressiveness against nestmates and aliens, i.e. their behavior towards other individuals.

Below, we relate and comment information on statins and we conclude.

Looking for information about effects of statins, we first discovered comments made by patients. These persons explain that they have pain in their muscles, and feel tired (https://www.meamedica.fr/cholesterol/ simvastatine, base-donnees-publique.medicaments. gouv.fr/affichageDoc.php?...N). More medical sites state that statins lead to muscular weakness, digestive problems, hypersensitivity to several factors, headache, tiredness (sante.journaldesfemmes.com > ... Simvastatine > Simvastatine EG $40 \mathrm{mg}$, santecheznous.com/drug/ getdrug/mylan-simvastatin,sante.canoe.ca/drug/ getdrug/mylan-simvastatin, www.passeportsante. net>Actualités>Nouvelles, ansm.sante.fr/var/ansm.../ c6090fc66b0777de27e12faf285d4be4.pdf). Finally, a recent website affirms that the effects of statins have not been, or have been poorly divulgated (cholesterol-verite. blogspot.com $/ 2013 / . . . /$ effets-secondaires-des-statines. ht...). This site lists the adverse effects often observed: they are those above mentioned together with other ones, such as some decrease of memory and even lost of memory. Of course, precaution must be taken when discussing our results in front of observations made on patients since ants largely differ from humans. However, some parallels can be made. For example, muscular pains, tiredness, memory difficulties observed in several patients are symptoms consistent with results we obtained i.e., general activity decrease, locomotion problems, cognition capabilities decrease, learning and memory large decreases. We noted that no website informs about an increase of sugared food consumption, a fact we observed on ants throughout the entire experimentation, i.e., during 22 days.

On the other hand, the latter cited site also state the danger of hypercholesterolemia have been exaggerated, and that statins act on very important molecules (Co A for instance) allowing good structure and functioning of mitochondria, nucleus, cellular membrane. We thus estimate that there exist two bodies of opinion. One affirms that a large amount of cholesterol is very dangerous, that reducing this amount is necessary, that this can efficiently be made by consuming statins, and that these drugs have nearly no adverse effects. The other body of opinion, illustrated by the latter cited websites, states that cholesterol is not dangerous under a limited amount, and that statins, though reducing effectively the amount of cholesterol, may have many adverse effects. These effects result from the physiological activity of statins: they inhibit the activity of important molecules. Two scientific works are in favor of the latter opinion ${ }^{20,21}$.

\section{Conclusion}

On basis of our experiments on ants, and on our bibliographical research, (and taking into account that ants' behavior is far different from that of humans), we conclude that statins may potentially have several adverse effects on physiology and behavior of patients, impacting among others, at least for a time, their sugared food consumption, their general activity, their locomotion, memory, cognition and "audacity".

However, statins surely efficiently reduce the amount of (not ingested but produced by the organism) cholesterol. Consequently, at our mind, statins should not be given to children, but should be used only for persons suffering from a severe hypercholesterolemia, and attention should be paid to these persons as for their sugared food consumption rate (never mentioned in the literature but observed on ants during 22 consecutive days), muscular function, general activity, memorization, and several cognitive abilities. Another not natural product has also been very recently set up for treating persons suffering from hypercholesterolemia: alirocumat (under the label repatha ${ }^{\circ}$, praluent ${ }^{\circ}$ ). Alirocumat is a monoclonal antibody which stops the activity of the enzyme PCSK9, 
a protein which prevents the degradation of cholesterol, and consequently cholesterol is degraded under that new product treatment. Even if very efficient in reducing the amount of cholesterol in blood, the antibody is an active protein and may have many other not yet known (or divulgated) side effects. Moreover, that drug is very expensive. Natural alternatives would be preferentially tried for treating common people suffering from hypercholesterolemia. Researchers in pharmaceutical sciences should thus search for some natural alternatives, such as adequate plants extract (e.g. Plantago ovata) or the recently recognized red yeast of rice. We recently examined the physiological and ethological effects of the latter product, using again ants as models, and found it was harmless on ants. If reducing efficiently the amount of cholesterol in blood, it could thus be used for treating persons suffering from moderate hypercholesterolemia ${ }^{22}$.

\section{Acknowledgements}

We sincerely thank an anonymous referee whose comments allowed us improving our text, and the Editor of the journal for taking the responsibility of publishing a paper demonstrating potential adverse effects of a largely used drugs.

\section{Ethical Considerations}

We affirm having maintained the ants in the best conditions possible; we declare we have no advantage at all with the production and the use of statins for caring of persons suffering from hypercholesterolemia.

\section{References}

1. Versmissen J, Oosterveer DM, Yazdanpanah M, Defesche JC, Basart DC, Liem AH et al. Efficacy of statins in familial hypercholesterolaemia: A long term cohort study [archive]. BMJ. 2008; 337. DOI: Crossref.

2. Armitage J. The safety of statins in clinical practice [archive]. Lancet. 2007; 370:1781-90.

3. Cammaerts M-C. Ants as biological models for studying effects of substances used by humans. JSM Anat Physiol. 2016; 1(1):1003.

4. Cammaerts M-C, Cammaerts R. Ethological and physiological effects of paroxetine, the nowadays most consumed antidepressant. A study on ants as models. Current Topics in Pharmacology. 2016; 12:107-26.

5. Cammaerts M-C, Cammaerts D, Rachidi Z. Potential harmful effects of carbamazepine on aquatic organisms, a study using ants as invertebrate models. Int J Biology. 2015; 7(3):75-93. ISSN 1916-9671 E-ISSN 1916-968X.

6. Wehner R, Gehring W. Biologie et Physiologie Animales. De Boek Université, Thieme Verlag: Paris, Bruxelles; 1999.

7. Wolf FW, Heberlein U. Invertebrate models of drug abuse. J Neurobiol. 2003; 54:161-78. Available from: Crossref.

8. Andre RG, Wirtz RA, Das YT. Insect models for biomedical research. In: Woodhead AD, editor. Non mammalian Animal Models for Biomedical Research. Boca Raton, FL: CRC Press; 1989.

9. Keller RA. A phylogenetic analysis of ant morphology (Hymenoptera: Formicidae) with special reference to the Poneromorph subfamilies. Bull Am Museum Nat Hist. 2011; 355:1-90.

10. Billen J, Morgan ED. Pheromone communication in social insects- sources and secretions. In: Vander Meer RK, Breed MD, Espelie KE, Winston MLK, editors. Pheromone Communication in Social Insects: Ants, Wasps, Bees, and Termites; Westview Press: Boulder, Oxford; 1998.

11. Passera L, Aron S. Les fourmis: comportement, organisation sociale et évolution. Ottawa Canada: Les Presses Scientifiques du CNRC; 2005.

12. Hölldobler B, Wilson EO. The ants. Harvard University Press. Berlin: Springer-Verlag; 1990.

13. Cammaerts M-C, Cammaerts D. Comparative outlook over three Myrmica species' biotopes and foragers' knowhow. Biologia. 2014; 69:1051-8. Crossref.

14. Cammaerts MC, Cammaerts R. Ontogenesis of ants' cognitive abilities (Hymenoptera, Formicidae). Advanced Studies in Biology. 2015; 7:335-48 + synopsis: 349-50.

15. Cammaerts MC, Gosset G. Impact of age, activity and diet on the conditioning performance in the ant Myrmica ruginodis used as a biological model. Int J Biol. 2014; 6: 10-20. ISSN 1916-9671 E-ISSN 1916-968X

16. Cammaerts M-C, Dero A, Cammaerts R. Stevia: A true glycoside used as a sweetener and not affecting behavior. Asian J Pharm Res Healthcare. 2016; 8(1):19-31.

17. Cammaerts M-C, Cammaerts R, Rachidi Z. Effects of four plants extract used as an anxiolytic: A study on ants as models. Adv Biomed Pharma. 2016; 3(5):280-95.

18. Siegel S, Castellan NJ. Non-parametric statistics for the behavioural sciences. Singapore: McGraw-Hill Book Company; 1989.

19. Cammaerts MC, Morel F, Martino F, Warzée N. An easy and cheap software-based method to assess two-dimensional trajectories parameters. Belg J Zool. 2012; 142:145-51.

20. Wagstaff LR, Mitton MW, Arvik BM, Doraiswamy PM. Statin-associated memory loss: analysis of 60 case reports and review of the literature. Pharmacotherapy. 2003; 23:871-80.

21. Sathasivam S, Lecky B. Statin induced myopathy [archive]. BMJ. 2008; 337. Crossref.

22. Cammaerts MC. Adverse effects of a natural product allowing decreasing the amount of cholesterol in blood: A study using ants as models. MOJ Biol Med. 2017; 1(3):00013. Crossref. 